

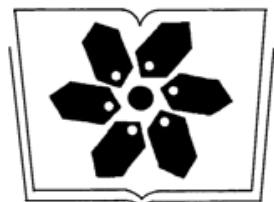

中国科学院科学出版基金资助出版
生 态 学 报

(SHENGTAI XUEBAO)

第 34 卷第 12 期 2014 年 6 月 (半月刊)

中国景观生态学发展历程与未来研究重点 陈利顶,李秀珍,傅伯杰,等 (3129) 城市景观格局演变的水环境效应研究综述 黄 硕, 郭青海 (3142) 多功能景观研究进展 汤 茜, 丁圣彦 (3151) 空间形态受限型城市紧凑发展研究——以厦门岛为例 黄 硕, 郭青海, 等 (3158) 紫金山森林公园降温效应影响因素 间伟姣, 孔繁花,尹海伟,等 (3169) 城市公园景观空间结构对其热环境效应的影响 冯悦怡, 胡潭高, 张力小 基于 OWA 的低丘缓坡建设开发适宜性评价——以云南大理白族自治州为例

刘炎序,彭 建, 韩忆楠,等 (3188) 生态安全条件下土地利用格局优化——以皇甫川流域为例 喻 锋, 李晓兵, 王 宏 (3198) 新疆玛纳斯河流域 2000-2010 年土地利用/覆盖变化及影响因素. 刘金巍, 靳甜甜,刘国华,等 (3211) 基于 GIS 和 RS 的赣江上游流域土地利用动态趋势分析 鲁燕飞,彭 芳,万 韵,等 (3224) 1954-2010 年三江平原土地利用景观格局动态变化及驱动力 刘吉平, 赵丹丹,田学智, 等 (3234) 基于斑块评价的三峡库区腹地坡耕地优化调控方法与案例研究 王永艳, 李阳兵, 郡景安,等 (3245) 贵州省山地-坝地系统土地利用与景观格局时空演变 李阳兵,姚原温,谢静,等 (3257) 中国西南地区土地覆盖情景的时空模拟 李 婧, 范泽孟, 岳天祥 (3266) 基于移动窗口法的峎江干旱河谷景观格局梯度分析. 张玲玲, 赵永华, 殷 莎, 等 (3276) 基于植被覆盖度的藏羚羊栖息地时空变化研究 赵海迪, 刘世梁, 董世魁, 等 (3285) 西南峡谷型喀斯特坡地土壤微生物量 $\mathrm{C} 、 \mathrm{~N} 、 P$ 空间变异特征 范夫静,黄国勤,宋同清,等 (3293) 峡谷型喀斯特不同生态系统的土壤微生物数量及生物量特征 谭秋锦, 宋同清, 彭晚霞, 等 (3302) 长三角地区土地利用时空变化对生态系统服务价值的影响 刘桂林, 张落成, 张 倩 (3311) 基于视觉廊道的青藏铁路沿线旅游动态景观评价 张瑞英,席建超,姚予龙,等 (3320) 基于 RS 与 GIS 的农村居民点空间变化特征与景观格局影响研究 任 平, 洪步庭, 刘寅,等 (3331) 生态系统保护现状及保护等级评估—以江西省为例 樊乃卿, 张育新, 吕一河,等 (3341) 崇明东滩盐沼植被变化对滩涂湿地促淤消浪功能的影响 任璘婧,李秀珍,杨世伦,等 (3350) 基于气候、地貌、生态系统的景观分类体系——新疆地区为例 .... 师庆东, 王 智, 贺龙梅, 等 (3359) 黄土丘陵沟壑区景观格局演变特征——陕西省延安市为例 钟莉娜, 赵文武, 吕一河, 等 (3368) 不同千扰背景下农业景观异质性——以巩义市为例 张晓阳,梁国付,丁圣彦 (3378) 山西高原草地景观的数量分类与排序 张先平, 李志琴, 王孟本, 等 (3386) 
山区夏季地表温度的影响因素 以泰山为例 孙常峰, 孔繁花, 尹海伟, 等(3396)

典型岩溶洼地土壤水分的空间分布及影响因素 张继光, 苏以荣, 陈洪松, 等 (3405)

基于移动窗口法的豫西山地丘陵地区景观异质性分析…… 李栋科, 丁圣彦, 梁国付, 等 (3414)

桂西北喀斯特区域植被变化趋势及其对气候和地形的响应 童晓伟, 王克林, 岳跃民, 等 (3425) 喀斯特与非喀斯特区域植被覆盖变化景观分析 以广西壮族自治区河池市为例

汪明冲, 王兮之, 梁钊雄, 等 (3435)

不同千扰背景下景观指数与物种多样性的多尺度效应 以巩义市为例

董翠芳, 梁国付, 丁圣彦, 等 (3444)

石栋-青冈常绿阔叶林土壤有机碳和全氮空间变异特征 杨 丹, 项文化, 方 晰, 等 (3452) 湘中丘陵区南酸柬阔叶林群落特征及群落更新 易 好, 邓湘雯, 项文化, 等 (3463) 基于 RBFN 的桂西北喀斯特区植被碳密度空间分布影响因素分析....... 张明阳, 王克林, 邓振华, 等 (3472)

期刊基本参数: CN 11-2031/Q * $1981 * \mathrm{~m} * 16 * 352 * \mathrm{zh} * \mathrm{P} * ¥ 90.00 * 1510 * 36 * 2014-06$

封面图说: 空间发展受限城市的厦门一一在我国城市化进程中, 中小城市在城镇体系建设中处于中间环节, 起到了联系大城市 和小城镇的作用。但是,每个城市由于发展历史、社会经济结构、自然地理形态等因素的不同,都有其发展的特性, 这些问题都必须要因地制宜地去把握。例如, 厦门岛相对隔离, 没有多余的发展空间, 该城市以居住功能为主, 城市 功能较为单一, 公共服务功能和商业服务功能比例较小。研究这样紧凑型的城市发展必须要考虑该城市结构转换 的承受力, 周边社会经济环境以及居民的生活习惯等。

彩图及图说提供: 陈建伟教授 北京林业大学 E-mail: cites.chenjw@163.com 
任璘婧, 李秀珍, 杨世伦, 间中正, 黄星.崇明东滩盐沼植被变化对滩涂湿地促淤消浪功能的影响.生态学报,2014,34(12):3350-3358.

Ren L J, Li X Z, Yang S L, Yan Z Z, Huang X.The impact of salt marsh change on sediment accumulation and wave attenuation at the East Chongming Island.Acta Ecologica Sinica, 2014,34(12):3350-3358.

\title{
崇明东滩盐沼植被变化对 滩涂湿地促淤消浪功能的影响
}

\author{
任璘婧，李秀珍 *，杨世伦，间中正，黄 星 \\ (华东师范大学 河口海岸学国家重点实验室, 上海 200062)
}

摘要:30 年来在海平面上升、人类围圼、自然保护、外来物种人侵等自然与人为作用共同影响下, 崇明东滩盐沼植被群落结构发 生了巨大变化。基于长江口四期遥感影像解译结果, 得到盐沼植被群落结构变化, 结合对盐沼植被促淤消浪功能已有研究成 果, 量化崇明东滩盐沼植被促淤消浪功能潜力及其变化。研究表明: 1980、1990、2000 和 2010 年崇明东滩芦苇、互花米草、蔍草 群落面积比例分别为 23:0:77、73:0:27、33:9:58、34:34:32, 同期总植被覆盖面积分别为 $51 、 83 、 37 、 44 \mathrm{~km}^{2}$ 。3 年来滩涂湿地促淤 消浪能力均有下降, 1990-2000 年变化最大。其中, 植被黏附悬浮颗粒物量分别为 1976、4645、2192、4695 $\mathrm{t}$; 沉积量分别为 960、 $1579 、 195 、 286$ 万 $\mathrm{m}^{3}$; 常规波高情况下堤外没有足够植被保护的岸段长度分别为 $5 、 0 、 7 、 6 \mathrm{~km}$; 风暴潮情况下堤外没有足够植被 保护的岸段长度分别为 $19 、 5 、 26 、 20 \mathrm{~km}$ 。因此保护堤外盐沼植被对消浪促淤, 特别是抵御风暴潮等恶劣气候灾害的影响具有 重要意义。

关键词:崇明东滩;盐沼植被;植被黏附悬浮颗粒物;促淤;消浪

\section{The impact of salt marsh change on sediment accumulation and wave attenuation at the East Chongming Island}

REN Linjing, LI Xiuzhen *, YANG Shilun, YAN zhongzheng, HUANG Xing

State Key Laboratory of Estuarine and Coastal Research, East China Normal University, Shanghai 200062, China

Abstract: As a key part of substance and energy exchange between land and ocean, estuarine wetland is the hotspot and focus of multiple disciplines. Under natural and artificial influences such as sea level rising, human reclamation, nature conservation, and exotic species invasion, salt marsh in the East Chongming wetlands had undergone severe changes during the past decades. Based on field investigation, remotely sensed images were classified and corrected for the periods of 1980 , 1990, 2000 and 2010 at the East Chongming Island. In combination with existing research results, the impact of salt marsh change on sediment accumulation and wave attenuation of the East Chongming wetlands were quantified. The results showed that: the area ratio of Phragmites/Spartina/Scirpus were 23:0:77, 73:0:27, 33:9:58 and 34:34:32 in 1980, 1990,2000 and 2010 , respectively, with the total area of salt marsh vegetation changed from $51 \mathrm{~km}^{2}$ to $83 \mathrm{~km}^{2}, 37 \mathrm{~km}^{2}$ and $44 \mathrm{~km}^{2}$. Under constant sedimentation during 1980-1990, the total amount of suspended particulate matter adhered by vegetation increased by $2669 \mathrm{t}$, while the amount of sediment accumulation increased by $619 \times 10^{4} \mathrm{~m}^{3}$. The length of seawall without enough vegetation protection under normal tidal heights and under storm surge decreased by $5 \mathrm{~km}$ and $14 \mathrm{~km}$, respectively. Due to intensive human reclamation during 1990-2000, the total amount of suspended particulate matter adhered by

基金项目:科技部全球变化研究国家重大科学研究计划 (2010CB951203); 国家自然科学基金(41271065,41130856); 上海市科委“创新行动计 划”计划( 13231203500) 资助

收稿日期: 2013-11-04; 修订日期: 2014-04-01

*通讯作者 Corresponding author.E-mail: xzli@ sklec.ecnu.edu.cn 
vegetation decreased by $2453 \mathrm{t}$, the amount of sediment accumulation decreased by $1384 \times 10^{4} \mathrm{~m}^{3}$. The length of seawall without enough vegetation protection under normal tides and under storm surge increased by $7 \mathrm{~km}$ and $21 \mathrm{~km}$, respectively. With the influences of constant sedimentation and exotic species invasion during 2000-2010, the total amount of suspended particulate matter adhered by vegetation increased by $2503 \mathrm{t}$, and sediment accumulation increased by $91 \times 10^{4}$ $\mathrm{m}^{3}$. The length of seawall without enough protection under normal tides and under storm surge decreased to $6 \mathrm{~km}$ and 20 $\mathrm{km}$, respectively. Saltmarsh vegetation protection is of great importance for land accretion and for the safety behind the seawall, in addition to its importance for a number of other ecological functions such as bio-productivity, biodiversity, and purification.

Key Words: East Chongming Island; salt marsh vegetation; total suspended particulate matter adhered; sediment accumulation; wave attenuation

河口滩涂湿地是陆地与海洋之间物质能量交换 的重要环节, 潮汐、盐淡水交汇、冲淤演变、植被演替 等等各种物理、化学和生物过程在这里相互作用,形 成了一个复杂的系统, 是综合多学科研究的热点与 难点 ${ }^{[1]}$ 。崇明东滩滩涂湿地具有气候调节、物质生 产、净化环境、生物多样性保育等重要生态系统服务 功能 ${ }^{[2]}$ 。除此之外, 随着经济的发展, 土地资源不 足,滩涂湿地盐沼植被促淤消浪等对海岸沉积动力 过程的影响,在海平面上升背景下, 日益受到国内外 研究者的高度重视 ${ }^{[3 \mathrm{i} d 6]}$ 。滩涂盐沼植被是粗糙下垫 面, 可增大水流摩擦阻力, 减缓水流, 影响泥沙运输, 达到促淤消浪的作用, 这对于滩涂水沙动力环境, 冲 淤演变以及滩涂发育有多重意义: 植被黏附水体中 悬浮颗粒物有助于净化水质, 植被促进泥沙淤积有 利于滩涂湿地维持,植被消浪缓流作用保证了海堤 安全 ${ }^{[1,6-7]}$ 。

近年来,大规模的滩涂围层、外来物种互花米草 (Spartina alterniflora) 人侵等自然人为因素对崇明东 滩景观格局造成了巨大影响 ${ }^{[8-10]}$ 。盐沼植被群落结 构的改变造成了一系列的生态效应,植被促淤、消浪 功能的巨大变化就是其中最重要的两项。研究自然 滩涂湿地植被结构对其功能造成的影响，既是对“景 观格局一过程” 关系研究的贡献,也有助于更好地了 解盐沼植被的多重生态功能, 为今后的围剭与保护 提供决策依据。

\section{1 研究区域与方法}

\section{1 研究区概况}

崇明东滩位于上海市崇明岛最东端 $\left(31^{\circ} 26^{\prime}\right.$ $31^{\circ} 37^{\prime} \mathrm{N} 、 121^{\circ} 46^{\prime}-122^{\circ} 02^{\prime} \mathrm{E}$ ), 长江人海口处。由
长江径流携带的泥沙沉积而成 ${ }^{[1]}$ 。研究区为 1980 年、1990 年、2000 年、2010 年卫星影像上提取的海堤 以外的自然滩涂区域,南起奚家港北至北八滧港 (图 1)。崇明东滩地属亚热带季风气候, 全年气候温和、 空气湿润、四季分明。年均温度 $15.3^{\circ} \mathrm{C}, 7-8$ 月份最 热, 月平均气温达到 $27.8{ }^{\circ} \mathrm{C}, 1$ 月份最冷, 月平均气 温仅为 $3.5^{\circ} \mathrm{C}$, 年均降雨量 $1100-1200 \mathrm{~mm}$ 。长江大 通站 1951-2010 年年均径流量达 9000 亿 $\mathrm{m}^{3}$, 年均 输沙量 4.1 亿 $\mathrm{t}^{[11-12]}$ 。1990 年代后, 受长江流域修建 水库以及水土整治工程的影响, 长江人海输沙量近 年已减少至 1.5 亿 $\mathrm{t}^{[13-14]}$,使河口区地貌的冲淤格局 发生了较大的变化 ${ }^{[15]}$ 。长江河口处于非正规半日 浅海潮流区, 崇明东部潮滩多年平均潮差为 $2.50 \mathrm{~m}$ 左右 ${ }^{[16]}$ 。

崇明东滩主要分布 3 种典型盐沼植被群落:蔍 草 ( Scirpus spp.) 群落、互花米草（Spartina alterniflora) 群落以及芦苇 (Phragmites australis) 群 落。蔍草群落主要包括海三棱蔍草 ( Scirpus mariqueter)、糙叶苔草 ( S. scabrifolia) 和蔍草 ( $S$. triqueter), 它们在盐度、潮位不同的滩地,形成单优势 或混合群落。因高度、密度、外貌特征等相似, 统称 为荛草群落。 20 世纪 90 年代中后期互花米草引人 以前, 崇明东滩盐沼植被先锋物种海三棱荛草主要 分布在中潮滩, 芦苇群落分布在高潮滩。互花米草 人工引种并成功定居之后, 逐渐扩散, 侵占芦苇和薦 草群落生态位,形成相互竞争的局面，严重排挤了 土著种的生长, 逐渐成为研究区的优势物种之 - ${ }^{[17]}$ 。互花米草人侵对无脊椎动物群落、涉禽种类 和数量、鱼类生境以及滩涂自然环境等均造成了一 定的负面影响 ${ }^{[18]}$ 。但是互花米草高生产力、固堤护 
岸、消浪促淤、围剭造陆等正面生态功能也不容 忽视。

近年来, 崇明东滩主要进行了 3 次大围旺: 1990 - 1993 年围垦了 $60.77 \mathrm{~km}^{2}$; 在 1996-1997 年 和 1998-1999 年分别围圼了 $9.14 \mathrm{~km}^{2}$ 和 $23.13 \mathrm{~km}^{2}$,
2001 年在崇明岛南部再次围垦约 $6 \mathrm{~km}^{2[9]}$ 。大面积 的堤外滩涂湿地不断被人工围层后用作人工库塘、 农业用地、建筑用地等,也有一部分仍为半自然状态 下的堤内湿草甸。

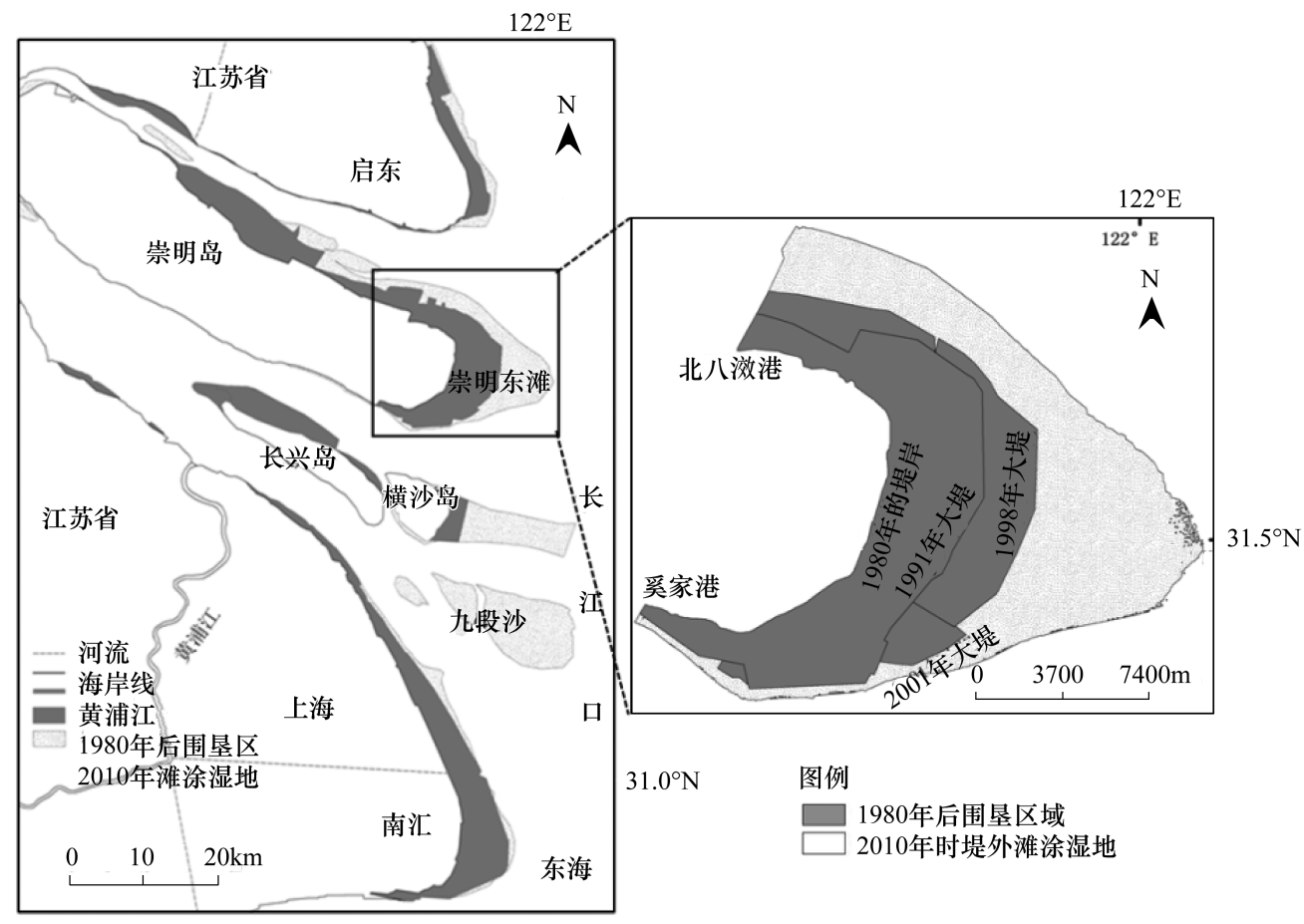

图 1 研究区域示意图

Fig.1 The study area

\section{2 数据来源}

本文使用的四期卫星影像数据分别为: 1980 年 10 月 27 日 MSS 数据 (分辨率 $79 \mathrm{~m}$ )、1990 年 12 月 4 日、2000 年 6 月 14 日 TM 数据 (分辨率 $30 \mathrm{~m}$ ) 以及 2010 年 2 月 21 日北京一号小卫星影像数据( 分辨率 $32 \mathrm{~m})$ 。通过 Erdas9.3 和 Arcgis 10.0, 分别对堤内和 堤外部分进行监督分类和目视解译, 野外实地考察 和走访后, 对解译结果进行了修订, 最终得到 4 个时 期的景观类型分布图。其中光滩部分, 由于每幅遥 感影像拍摄时的潮位不同,潮间带下部光滩面积可 能存在一定误差,在解译过程中已经与潮位表、海图 等进行过校正,尽量减小此部分误差。经分类精度 评价,多期影像解译精度均达到 $85 \%$ 以上。根据解 译结果统计的各植被群落分布面积见图 2 。

\section{3 植被黏附悬浮颗粒物计算方法}

根据 $\mathrm{Li}$ 等 ${ }^{[12]}$ 对崇明东滩 3 种典型植被芦苇、互 花米草、海三棱蔍草黏附悬浮颗粒物的差异性研究, 单位滩地面积的互花米草群落总黏附量为 (220.6土
172.7) $\mathrm{g} \cdot \mathrm{m}^{-2} \cdot \mathrm{a}^{-1}$, 明显高于相邻芦苇群落 $(64.9 \pm$ $38.1) \mathrm{g} \cdot \mathrm{m}^{-2} \cdot \mathrm{a}^{-1}$ 和海三棱蔍草群落 $(31.6 \pm 10.0)$ $\mathrm{g} \cdot \mathrm{m}^{-2} \cdot \mathrm{a}^{-1}$ 。再结合解译出的植被面积,估算 30 年 来崇明东滩 3 种典型盐沼植被群落黏附悬浮颗粒物 总量变化趋势。

\section{4 植被促淤功能计算方法}

根据杨世伦等在 2008-2012 年对崇明东滩 3 条断面沉积速率月测量记录, 总结出芦苇群落、互花 米草群落、海三棱蔍草群落年沉积速率分别为 $(29.4 \pm 27.4) 、(108.7 \pm 80.6) 、(57 \pm 47) \mathrm{mm} / \mathrm{a}^{[19]}$ 。但 由于互花米草自身累积沉积物的能力较强, 其引种 后分布面积不断扩张, 破坏了植被原有的分带性, 减 少其他靠岸生长植被的沉积速率 ${ }^{[20]}$ 。根据刘英文 等研究,崇明东滩 1982-1990 年滩面(包括光滩) 平 均沉积速率为 $190 \mathrm{~mm} / \mathrm{a}^{[21]}$ 。通过遥感数据解译结 果,估算不同年份不同类型植被沉积量以及总的沉 积量。 


\section{5 植被消浪功能计算方法}

Yang 等在崇明东滩连续观测潮汛期不同水深 不同植被带对波高波能的消减速率, 研究发现光滩、 海三棱蔍草、互花米草对波高的消减率分别为 $0.091 \% / \mathrm{m} 、 0.95 \% / \mathrm{m}$ 和 $1.3 \%-6.0 \% / \mathrm{m}^{[22-23]}$ 。数 据均在正常潮汛情况下测得。因芦苇与互花米草在 高度、密度、生物量等植被形态上均较类似, 我们假 设芦苇消浪能力与互花米草相同,估算出不同覆盖 类型将有效波高消减为 $0.01 \mathrm{~m}$ 以下所需要的宽度。 陈燕萍等研究发现,崇明东滩中部中潮滩潮周期平 均有效波高为 $(0.13 \pm 0.09) \mathrm{m}$, 在向岸强台风和大潮 高潮位阶段,崇明东滩中潮线附近的最大波高可达 $1.5-2 \mathrm{~m}^{[24]}$ 。Tom Ysebaert 等在崇明东滩潮汛期, 并伴有向岸强风的情况下,测到最大水深 $1.86 \mathrm{~m}$, 最 大波高 $0.64 \mathrm{~m}$, 此时海三棱蔍草群落已完全被淹没, 消浪能力已几乎为零, 监测不到, 互花米草也已大部 分被淹, 消浪能力有限 ${ }^{[22]}$ 。那么在波高 $2 \mathrm{~m}$ 的风暴 潮情况下,可以推断光滩、海三棱蔍草群落几乎没有 消浪能力, 互花米草消浪能力也非常有限。根据史 本伟等在日常测得的每米互花米草能消除有效波高 $4.4 \times 10^{-3} \mathrm{~m}$, 可以保守推断,要消除 $2 \mathrm{~m}$ 的波高, 所需 要的互花米草群落或芦苇群落最小宽度 ${ }^{[7]}$ 。用 Arcgis10.0 测量堤外不同植被类型分布宽度后，可以 估算出不同年份堤外没有足够植被保护的岸段 长度。

\section{2 结果与分析}

\section{1 堤外盐沼植被景观格局演变}

由于长江河口水沙变化, 河床冲淤变化, 围垦工 程实施, 以及外来物种互花米草的人侵、植被自然演 替等,堤外自然湿地 30 年来植被组成与面积均发生 了巨大变化。1980 年、1990 年、2000 年、2010 年,有 植被覆盖的自然湿地面积分别为 $51 、 83 、 37 、 44 \mathrm{~km}^{2}$ (图 2), 芦苇、互花米草、蔍草 3 种主要盐沼植被群 落面积比例分别为 $23: 0: 77 、 73: 0: 27 、 33: 9: 58$ 、 $34: 34: 32$ 。其中, 土著先锋蔍草群落由 1980 年最多 时的 $39 \mathrm{~km}^{2}$ 减少到 2010 年的 $14 \mathrm{~km}^{2}$ 。芦苇群落由 最多时的 $60 \mathrm{~km}^{2}$ 减少到 2010 年的 $15 \mathrm{~km}^{2}$ 。

相反,外来物种互花米草却由 1980 年、1990 年 的 $0 \mathrm{~km}^{2}$, 不断增加到 2000 年的 $3 \mathrm{~km}^{2}$ 以及 2010 年的 $15 \mathrm{~km}^{2}$,扩张迅速,到 2010 年已成为分布面积最大
的盐沼植被之一。

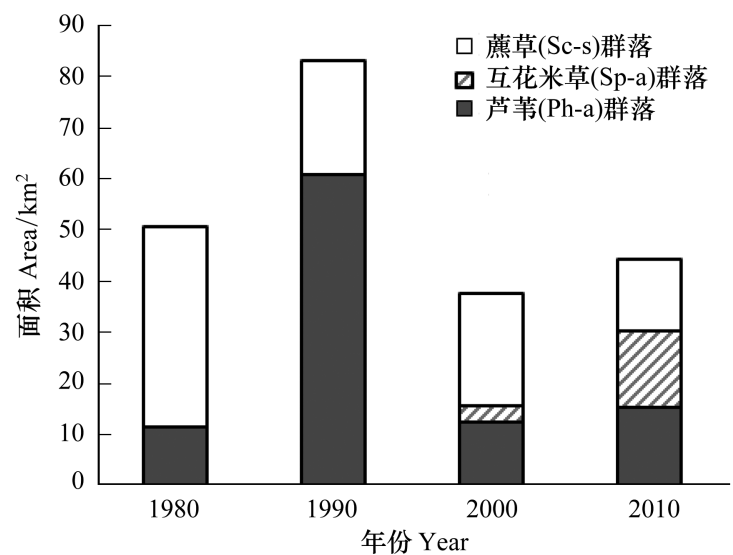

图 2 崇明东滩 3 种典型盐沼植被群落面积变化

Fig.2 The area change of three typical salt marsh communities in East Chongming

从植被前沿扩展速率来看, 1980-1990 年约为 $180 \mathrm{~m} / \mathrm{a}, 1990$ - 2000 年为 $280 \mathrm{~m} / \mathrm{a}, 2000-2010$ 年 为 $190 \mathrm{~m} / \mathrm{a}$ 。因此, 1990-2000 年扩展速率最快, 与 这段时间的高强度围垦相呼应。但堤外自然植被的 实际面积却以 2000 年最低 (图 2)。因此,围垦虽然 促进了盐沼植被的快速东扩,但难以弥补由此带来 的面积损失。

2.2 盐沼植被变化对植被黏附悬浮颗粒物量的影响

植被黏附悬浮颗粒物总量 30 年来的变化见图 4 , 总体上呈现波动态势。1990 年时植被总黏附悬浮 颗粒物量最大, 达到 $4645 \mathrm{t}, 2000$ 年最少, 为 $2192 \mathrm{t}$, 不到 1990 年最高时的二分之一。其中芧草群落黏 附量由 1980 年的 $1237 \mathrm{t}$ 减少到 2010 年 $444 \mathrm{t}$, 芦苇 群落除 1990 年时达到 $3936 \mathrm{t}$, 占 1990 年总量的 $85 \%$ 外,其他年份相差不大, 互花米草群落却由 $0 \mathrm{t}$ 迅速 增加到 $3265 \mathrm{t}$, 占 2010 年总量的 70\%。究其原因, 1980-1990 年间,伴随着滩面淤高迅速, 尤其是高潮 滩不断向外淤涨, 盐沼植被面积不断扩大, 尤其是芦 苇群落, 而芦苇黏附县浮颗粒物能力更是海三棱蔍 草的 1.5 倍左右, 因此植被黍附悬浮颗粒物总量增加 了近 1 倍 ${ }^{[6]}$ 。1990-2000 年,东滩一共经历了 3 次 大规模的围垦,滩涂面积不断缩小,大面积的芦苇群 落被围进大堤内, 导致堤外盐沼植被黏附悬浮颗粒 物总量迅速减少 ${ }^{[9]}$ 。2000-2010 年, 是外来物种互 花米草的快速增长期,而互花米草黏附悬浮颗粒物 的能力远远大于其他两个土著种, 几乎是芦苇、海三 棱蔍草的 3.5 倍和 5 倍,因此 10 年间植被黏附悬浮 
颗粒物总量大大增加, 2010 年已到达 2000 年的 2 倍多。
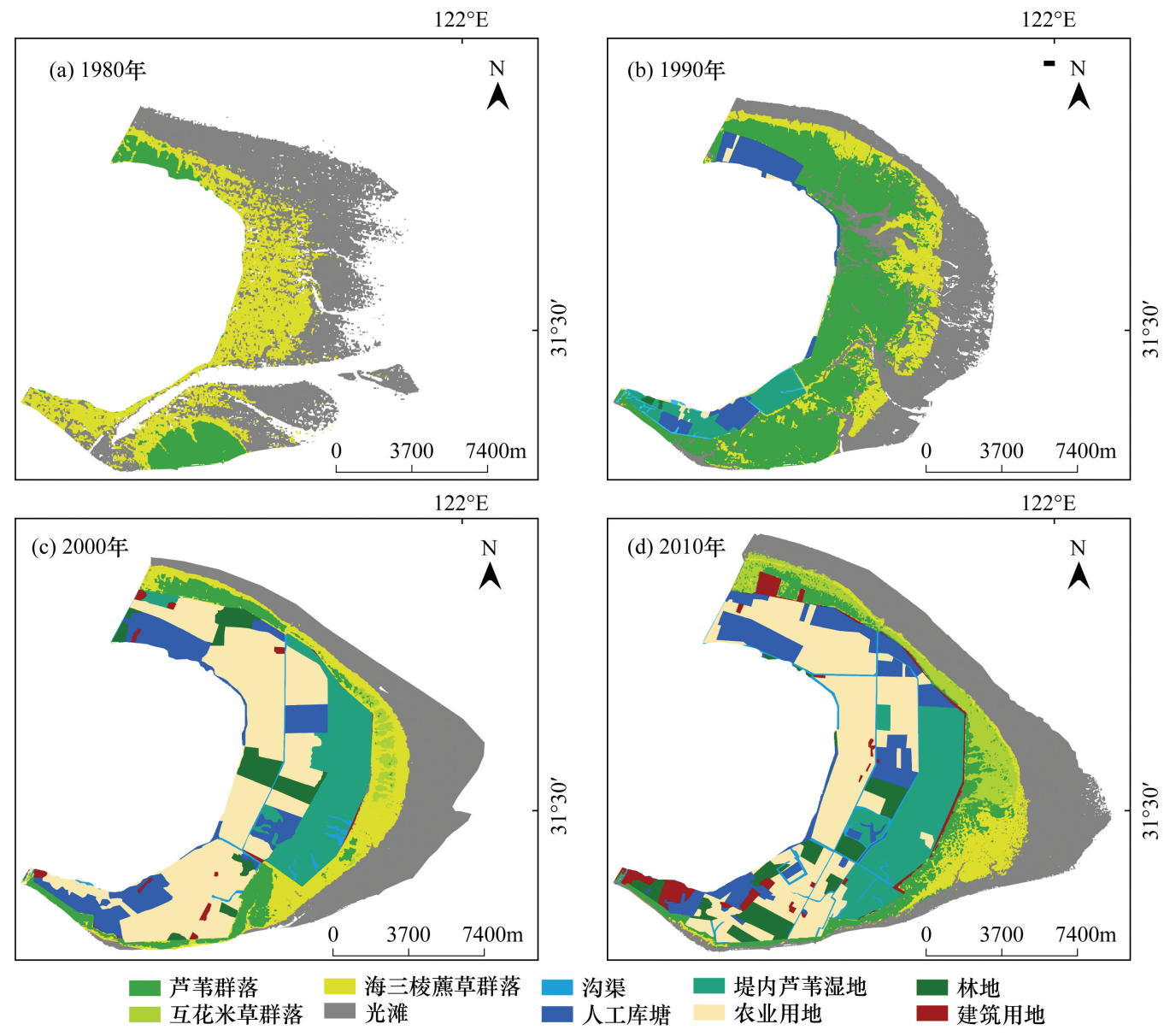

图 3 崇明东滩滩涂湿地类型分布图 (1980-2010 年)

Fig.3 The classification map of the estuary wetlands in East Chongming (1980-2010)

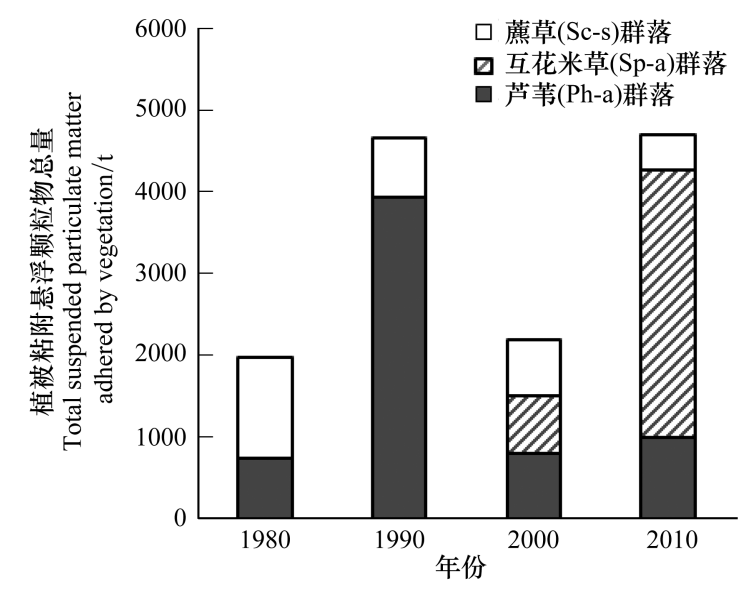

图 430 年来植被黏附悬浮颗粒物总量变化

Fig. 4 The change of total suspended particulate matter adhered by vegetation

\section{3 盐沼植被促淤功能的变化}

随着分布面积的变化,3 种典型盐沼植被群落年 沉积量也发生了巨大变化( 图 5 )。互花米草引种以
及大面积人工围剭之前的 1980 年、1990 年崇明东滩 盐沼植被年沉积量分别达到 960 万 $\mathrm{m}^{3}$ 和 1579 万 $\mathrm{m}^{3}$, 由于芦苇面积的增加, 1990 年沉积量增加了 $39 \%$ 。然而, 1990-2000 年 $93 \mathrm{~km}^{2}$ 的滩涂湿地 (包括 光滩) 遭到了人工围怎, 比 1990 年崇明东滩有植被 覆盖的滩涂湿地总面积还要多 $10 \mathrm{~km}^{2}$,因此 2000 年 盐沼植被年沉积量减少到 195 万 $\mathrm{m}^{3}$,仅占 1990 年的 $12 \%$ 。到 2010 年, 随着互花米草人侵面积增加,盐 沼植被年沉积量增加到 286 万 $\mathrm{m}^{3}$ 。

蔍草群落年沉积量由 1980 年的 743 万 $\mathrm{m}^{3}$ 不断 减少到 2010 年的 80 万 $\mathrm{m}^{3}$,芦苇群落在 1990 年时年 沉积量最高达 1152 万 $\mathrm{m}^{3}$, 到 2010 年降至 45 万 $\mathrm{m}^{3}$, 而互花米草群落年沉积量却由 $0 \mathrm{~m}^{3}$ 迅速增加到 2010 年的 161 万 $\mathrm{m}^{3}$, 占到 2010 年植被带沉积总量的 $56 \%$ 。这些变化与植被促淤能力的大小, 以及分布 面积的变化密切相关。互花米草群落植被覆盖密 集、茎秆结实、枝叶繁茂,其多年平均沉积速率分别 
是芦苇群落、海三棱蔍草群落的 3.7 倍和 1.9 倍 ${ }^{[19]}$ 。

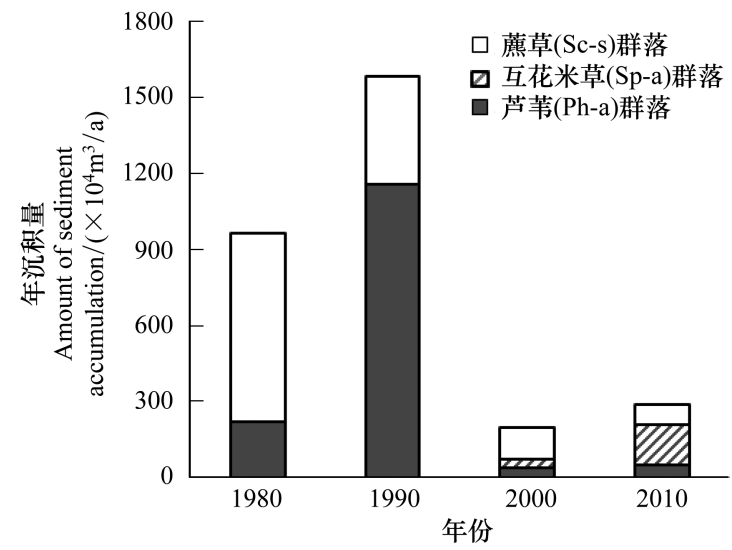

图 530 年来盐沼植被年沉积量变化

Fig.5 The estimated change in sediment accumulation in the last thirty years

根据唐玉姝等在崇明东滩南断面 (海岸冲 刷带, 有促淤坝) 和北断面 (海岸淤涨带, 无促淤坝) 测得的土壤容重平均值 $1.46 \mathrm{~g} / \mathrm{cm}^{3[25]}$, 可估算出 1980 年、1990 年、2000 年、2010 年盐沼植被年平均 沉积量分别为 $14.02 \times 10^{6} \mathrm{t} / \mathrm{a} 、 23.05 \times 10^{6} \mathrm{t} / \mathrm{a} 、 2.85 \times$ $10^{6} \mathrm{t} / \mathrm{a} 、 4.17 \times 10^{6} \mathrm{t} / \mathrm{a}$ 。然而 1980 -2010 年, 植被黏 附悬浮颗粒物总量年平均值分别为 $1976.37 \mathrm{t} / \mathrm{a}$ 、 $4645.27 \mathrm{t} / \mathrm{a} 、 2192.24 \mathrm{t} / \mathrm{a} 、 4695.34 \mathrm{t} / \mathrm{a}$, 分别仅占沉积 量的 $0.01 \% 、 0.02 \% 、 0.08 \% 、 0.11 \%$, 呈不断上升趋 势。虽然植被黏附悬浮颗粒物量占年沉积量的比例 相对较小,但其促进悬浮颗粒物沉降的作用仍不容 小㱆 ${ }^{[6,12]}$ 。

\section{4 盐沼植被消浪能力变化}

在常规波高情况下 $(0.13 \pm 0.09 \mathrm{~m})$, 如果使浪高 降低为 0 , 光滩至少需要 $5058 \mathrm{~m}$ 宽, 海三棱蔍草至少 需要 $482 \mathrm{~m}$ 宽, 互花米草至少需要 74-352 m 宽, 芦 苇至少需要 74-352 m 宽, 植被越高、越密,植被带 越宽其消浪缓流能力越高 ${ }^{[20]}$ 。根据史本伟等的观 测数据 ${ }^{[7]}$, 保守推断在风暴潮情况下, 要消除 $2 \mathrm{~m}$ 的 波高, 至少需要互花米草或芦苇群落 $450 \mathrm{~m}$ 。据此推 算发现,常规波高情况和风暴潮情况下,堤外没有足 够植被保护的岸段长度变化趋势基本一致(图 6)。 1990 年时这样的岸段长度均最少, 常规波高情况下 为 $0 \mathrm{~km}$, 风暴潮情况下为 $5 \mathrm{~km} ; 2000$ 年时存在风险 的岸段最长, 分别达到 $7 \mathrm{~km}$ 和 $26 \mathrm{~km}$, 增加了 $7 \mathrm{~km}$ 和 $21 \mathrm{~km}$ 。这是因为 1990 年时堤外芦苇群落分布最 广,而由于 1990-2000 年的多项围层工程, 大面积
芦苇湿地被围人堤内, 堤外植被分布面积有限; 到 2010 年随着滩涂向海逐渐淤涨, 植被扩张, 问题有所 缓解, 常规波高情况和风暴潮情况下, 堤外没有足够 植被保护的岸段长度分别减少到 $6 \mathrm{~km}$ 和 $20 \mathrm{~km}$ 。

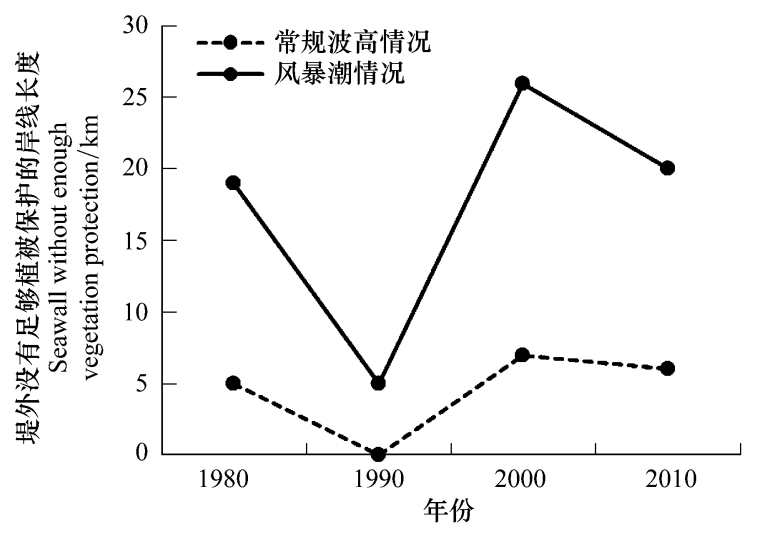

图 630 年来堤外没有足够植被保护的岸段长度变化 Fig.6 The estimated change of seawall without enough salt marsh vegetation protection in the last thirty years

\section{3 讨论}

通过估算 1980-2010 年崇明东滩盐沼植被变 化对滩涂湿地促淤消浪功能的影响 (表 1), 虽然盐 沼植被粘附悬浮颗粒物量增加了 $138 \%$,但其占沉积 量的比例仅为 $0.1 \%$ 左右, 而年沉积量在这 30 年却 减少了 $70 \%$,所以滩涂湿地促淤能力 30 年来呈下降 趋势。1980-2010 年, 不论在常规波高情况下还是 风暴潮情况下, 堤外没有足够植被保护的岸段长度 均有所增加。综上所述, 崇明东滩滩涂湿地促淤能 力和消浪能力 $1980-2010$ 年均呈下降趋势。

30 年来,在自然与人为因素的共同作用下,堤外 自然滩涂湿地景观格局发生了巨大变化 ${ }^{[26]}$ 。人类 围层和外来物种互花米草人侵就是其中两个最主要 的影响因素。研究发现虽然近 30 年崇明东滩围艮 面积大于 $100 \mathrm{~km}^{2[9]}$, 但有植被覆盖的滩涂湿地面积 仅比 1980 年减少了 $7 \mathrm{~km}^{2}(14 \%)$ 。正是由于植被巨 大的促淤消浪功能, 滩涂湿地才得以维持并继续 发育。

其中,外来物种互花米草就功不可没。互花米 草根系发达, 耐盐耐水淹, 繁殖能力、扩张能力强, 排 斥其他植物生长, 在与芦苇、海三棱蔍草的生态位竞 争中常常处于优势, 导致其面积自人侵以来不断扩 大 $^{[10]}$ 。植被群落结构的变化引发了一系列的生态 效应。外来物种互花米草人侵破坏鱼类、鸟类、底栖 
动物等的生境, 不利于生物多样性保育, 危害滩涂自 然环境及生态系统平衡 ${ }^{[18,27]}$ 。但是互花米草植株高 大茂密、抗逆性强, 有利于促淤造陆、固堤护岸 ${ }^{[21]}$ 。
到 2010 年, 互花米草以其 34\% 的植被面积, 对黏附 悬浮颗粒物量与促淤量的贡献已分别占到总量的 $70 \%$ 和 56\% ,均大于本土物种芦苇与蔍草群落。

表 1980 - 2010 年崇明东滩盐沼植被促淤消浪能力变化总结

Table 1 Summary of changes on sediment accumulation and wave attenuation in the salt marsh at the East Chongming Island

\begin{tabular}{|c|c|c|c|c|c|}
\hline \multicolumn{2}{|c|}{$\begin{array}{l}\text { 生态系统服务功能 } \\
\text { Ecosystem services }\end{array}$} & \multicolumn{2}{|c|}{ 年度 Year } & \multirow{2}{*}{$\begin{array}{c}\text { 变化量 } \\
\text { Net change }\end{array}$} & \multirow{2}{*}{$\%$} \\
\hline $\begin{array}{l}\text { 名称 } \\
\text { Name }\end{array}$ & $\begin{array}{l}\text { 相应内容 } \\
\text { Corresponding contents }\end{array}$ & 1980 & 2010 & & \\
\hline 促淤能力 & 黏附悬浮颗粒物量/t & 1976 & 4695 & +2719 & +138 \\
\hline Sediment accumulation & 沉积量 $/ 10^{6} \mathrm{t}$ & 14.02 & 4.17 & -9.85 & -70 \\
\hline 消浪能力 (不安全岸线长度) & 常规波高情况/km & 5 & 6 & +1 & +20 \\
\hline Wave attenuation (Length of unsafe seawall) & 风暴潮情况 $/ \mathrm{km}$ & 19 & 20 & +1 & +5 \\
\hline
\end{tabular}

由于诸多条件的限制,估算过程中也存在着一 些不足。

植被黏附悬浮颗粒物能力与许多外界因素密切 相关, 如河口地区悬沙浓度变化、淹水时间频率等 等。 $\mathrm{Li}$ 等 ${ }^{[28]}$ 研究发现, 1990-2010 年 20 年间,由于 流域人类活动影响, 长江人海泥沙大量减少, 河口地 区局部悬沙浓度下降了约 55\%,这必然会对植被实 际黏附悬浮颗粒物量产生一定影响。但据其他文献 报道, 由于在人类活动以及波浪和潮流共同作用下, 产生了泥沙再悬浮等现象, 海床的侵蚀不断地补充 悬沙 ${ }^{[14]}$ 。因此长江河口区域悬沙浓度是否减小仍 存在较大争议,有待于进一步明确 ${ }^{[29]}$ 。且由于植被 黏附悬浮颗粒物仅有 2005-2007 年的数据, 研究其 与河口地区悬浮泥沙浓度的关系有一定困难, 因此 还需要细致深人地针对此进行试验来完善。

此外李华 ${ }^{[6]}$ 等研究发现, 植被黏附悬浮颗粒物 量不仅有植被类型差异，还有位置、垂向与时间差 异, 随着距光滩或潮沟距离增加, 悬浮颗粒物含量减 小, 植被黏附量就降低; 随着淹水时间频率增加, 黏 附量从植物顶端向基部增加; 随着植被生物量增加, 黏附量增加, 在 9 月份达到饱和。不同植被类型的 垂向淤积速率也有类似的时空变化,本研究只考虑 了不同植被类型的平均黏附量和淤积量, 以后还需 要进一步分析植被空间分布对促淤功能估算结果的 影响。

由于有关早期崇明东滩不同植被类型沉积速率 的资料有限,因此采用了包括光滩在内的平均沉积 速率, 可能会相对高估 1980 年以及 1990 年盐沼植 被分布区的沉积量。
本研究中所采用的植被对有效波高的消减数据 均是在日常情况下测得, 并未获得风暴潮来临时不 同植被对波高的消减数据。当风暴潮来临, 水深加 深,植被大部分甚至全部被淹没时, 植被对有效波高 的消减作用会大幅降低 ${ }^{[22]}$ 。因此本文趋于低估了 风暴潮来临时堤外没有足够植被保护的岸段长度。

\section{4 结论}

在自然与人为因素共同作用下, 30 年来盐沼植 被群落结构发生了巨大变化, 导致崇明东滩滩涂湿 地促淤能力和消浪能力 1980-2010 年均呈下降趋 势。1980-1990 年随着滩涂淤涨, 植被黏附悬浮颗 粒物总量、沉积量以及植被消浪功能均迅速提高; 1990-2000 年伴随着大规模围垦工程, 堤外滩涂植 被大面积减少, 促淤消浪功能也快速降低; 20002010 年随着滩涂不断淤积以及互花米草快速扩张, 盐沼植被促淤消浪功能有所增加。因此, 在围垦大 堤之外保持一定面积、宽度的盐沼植被, 不但有利于 各项生态功能的发挥, 更有利于保障堤内的安全。

\section{References :}

[ 1 ] Ji X Q. A Study on Characteristics of Hydrodynamics and Sediment Transport, and Analysis of Vegetation Effects in Chongming Dongtan, Yangtze Estuary [D]. Shanghai : East China Normal University, 2008.

[ 2 ] Wu L L, Lu J J, Tong C F, Liu C Q. Valuation of wetland ecosystem services in the Yangtze River estuary. Resources and Environment in the Yangtze Basin, 2003, 12(5): 411-416.

[ 3 ] Bouma T J, De Vries M B, Low E, Kusters L, Herman P M J, Tánczos I C, Temmerman S, Hesselink A, Meire P, Regenmortel 
$\mathrm{S}$ V. Flow hydrodynamics on a mudflat and in salt marsh vegetation: identifying general relationships for habitat characterisations. Hydrobiologia, 2005, 540(1/3) : 259-274.

[ 4 ] Coulombier T, Neumeier U, Bernatchez P. Sediment transport in a cold climate salt marsh ( St. Lawrence Estuary, Canada), the importance of vegetation and waves. Estuarine, Coastal and Shelf Science, 2012, 101: 64-75.

[ 5 ] Moskalski S M, Sommerfield C K. Suspended sediment deposition and trapping efficiency in a Delaware salt marsh. Geomorphology, 2012, 139-140: 195-204.

[6] Li H, Yang S L. Changes of suspended particulates adhering to salt marsh plants. Acta Oceanologica Sinica, 2010, 32 ( 1 ): 114- 119 .

[ 7 ] Shi B W, Yang S L, Luo X X, Xu X J. A wave attenuation over the transitional zone of mudflat and salt marsh — a case study in the eastern Chongming on the Changjiang Delta. Acta Oceanologica Sinica, 2010, 32(3): 174-178.

[ 8 ] Huang H M, Zhang L Q, Yuan L. The spatio-temporal dynamics of salt marsh vegetation for Chongming Dongtan National Nature Reserve, Shanghai. Acta Ecologica Sinica, 2007, 27 ( 10 ): 4166-4172.

[ 9 ] Gao Y, Zhao B. The effect of reclamation on mud flat development in Chongming Island, Shanghai. Chinese Agricultural Science Bulletin, 2006, 22(8) : 475-479.

[10] Xiao D R, Zhang L Q, Zhu Z C. The range expansion patterns of Spartina alterniflora on salt marshes in the Yangtze Estuary, China. Estuarine, Coastal and Shelf Science, 2010, 88 (1): 99- 104 .

[11] Zhang E F, Savenije H H G, Chen S L, Chen J Y. Water abstraction along the lower Yangtze River, China, and its impact on water discharge into the estuary. Physics and Chemistry of the Earth, Parts A/B/C, 2012, 47-48: 76-85.

[12] Li H, Yang S L. Trapping effect of tidal marsh vegetation on suspended sediment, Yangtze Delta. Journal of Coastal Research, $2009,25(4)$ : 915-924.

[13] Yang S L, Zhang J, Zhu J, Smith J P, Dai S B, Gao A, Li P Impact of dams on Yangtze River sediment supply to the sea and delta intertidal wetland response. Journal of Geophysical Research: Earth Surface, 2005, 110(F3): F03006.

[14] Yang S L, Zhu J, Li M. Evolutional trend of the coastal wetland in Shanghai in response to decrease of sediment supply from the Changjiang River. Journal of Marine Sciences, 2009, 27 ( 2): 7- 15 .

[15] Li P, Yang S L, Dai S B, Zhang W X. Accretion / erosion of the subaqueous delta at the Yangtze Estuary in recent 10 years. Acta Geographica Sinica, 2007, 62(7) : 707-716.

[16] Zhao C Q, Mao Z C, Yu Z Y, Xu H G, Li J F. The analysis of the eastern Chongming tidal flats evolution in the Yangtze River estuary. Transactions of Oceanology and Limnology, 2008, (3) :
27-34.

[17] Li H P, Zhang L Q, Wang D H. Distribution of an exotic plant Spartina alterniflora in Shanghai. Biodiversity Science, 2006, 14 (2) : 114-120.

[18 Chen Z Y, Li B , Zhong Y, Chen J K. Local competitive effects of introduced Spartina alterniflora on Scirpus mariqueter at Dongtan of Chongming Island, the Yangtze River estuary and their potential ecological consequences. Hydrobiologia, 2004, 528 ( 1/3): 99- 106 .

[19] Li X Z, Ren L J, Liu Y, Christopher C, Ülo M, Yang S L. The impact of the change in vegetation structure on the ecological functions of salt marshes: the example of the Yangtze estuary. Regional Environmental Change, 2014, 14(2) : 623-632.

[20 ] Yang S L, Li H, Ysebaert T, Bouma T J, Zhang W X, Wang Y Y, Li P, Li M, Ding P X. Spatial and temporal variations in sediment grain size in tidal wetlands, Yangtze Delta: on the role of physical and biotic controls. Estuarine, Coastal and Shelf Science, 2008, 77(4): 657-671.

[21] Liu Y W, Yang S L, Luo X X. Separation estimate of beach erosion and deposition on intertidal wetland of the sea level rise and the normal deposition. Shanghai Land \& Resources, 2011, 32 (3) : 18-22.

[22 ] Ysebaert T, Yang S L, Zhang L Q, He Q, Bouma T J, Herman P M J. Wave attenuation by two contrasting ecosystem engineering salt marsh macrophytes in the intertidal pioneer zone. Wetlands, $2011,31(6)$ : 1043-1054.

[23] Yang S L, Shi B W, Bouma T J, Ysebaert T, Luo X X. Wave attenuation at a salt marsh margin: a case study of an exposed coast on the Yangtze Estuary. Estuaries and Coasts, 2012, 35 (1) : 169-182.

[24] Chen Y P, Yang S L, Shi B W, Li P, Zhu J R. Temporal and spatial variations in wave height over intertidal mudflats and the influencing factors: a case study from the Yangtze River Delta. Advances in Marine Science, 2012, 30(3) : 317-327.

[25 ] Tang Y S, Wang L, Jia J W, Li Y L, Zhang W Q, Wang H L, Fu X H, Le Y Q. The effect of artificial disturbance such as siltation promotion on soil microbial respiration of tidal wetlands in the Yangtze River estuary. Acta Ecologica Sinica, 2010, 30(18) : $5022-5032$.

[26] Li J F, Dai Z J, Ying M, Wu R R, Fu G, Xu H G. Analysis on the development and evoluation of tidal flats and reclamation of land resource along shore of Shanghai city. Journal of Natural Resources, 2007, 22(3): 361-371.

[27] Li B, Liao C Z, Zhang X D, Chen H L, Wang Q, Chen Z Y, Gan X J, Wu J H, Zhao B, Ma Z J, Cheng X L, Jiang L F, Chen J K. Spartina alterniflora invasions in the Yangtze River estuary, China: an overview of current status and ecosystem effects. Ecological Engineering, 2009, 35(4) : 511-520.

[28] Li P, Yang S L, Milliman J D, Xu K H, Qin W H, Wu C S, 
Chen Y P, Shi B W. Spatial, temporal, and human-induced variations in suspended sediment concentration in the surface waters of the Yangtze estuary and adjacent coastal areas. Estuaries and Coasts, 2012, 35(5): 1316-1327.

[29] Yang Y P, Li Y T, Sun Z H, Fan Y Y. Trends and causes of suspended sediment concentration variation in the turbidity maximum zone at the Yangtze River Estuary. Acta Geographica Sinica, 2013, 68(9): 1240-1250.

\section{参考文献:}

[ 1 ] 吉晓强. 崇明东滩水沙输移及植被影响分析 [D]. 上海: 华东 师范大学, 2008 .

[2] 吴玲玲, 陆健健, 童春富, 刘存岐. 长江口湿地生态系统服务 功能价值的评估. 长江流域资源与环境, 2003, 12(5): 411-416.

[ 6 ] 李华, 杨世伦. 潮间带盐沼植物黏附悬浮颗粒物的差异性研 究. 海洋学报, 2010, 32(1) : 114-119.

[ 7 ] 史本伟, 杨世伦, 罗向欣, 徐晓君. 淤泥质光滩-盐沼过渡带 波浪衰减的观测研究——长江口崇明东滩为例. 海洋学报, 2010, 32(2): 174-178.

[ 8 ] 黄华梅, 张利权, 袁琳. 崇明东滩自然保护区盐沼植被的时空 动态. 生态学报, 2007, 27(10): 4166-4172.

[ 9 ] 高宇, 赵斌. 人类围垦活动对上海崇明东滩滩涂发育的影响.
中国农学通报，2006，22(8): 475-479.

［14］杨世伦, Zhu J, 李明. 长江人海泥沙的变化趋势与上海滩涂 资源的可持续利用. 海洋学研究, 2009, 27(2) : 7-15.

[15］李鹏, 杨世伦, 戴仕宝, 张文祥. 近 10 年来长江口水下三角 洲的冲淤变化一一兼论三峡工程蓄水的影响. 地理学报, 2007, 62(7) : 707-716.

[16] 赵常青, 茅志昌, 虞志英, 徐海根, 李九发. 长江口崇明东滩 冲淤演变分析. 海洋湖沼通报, 2008, (3) : 27-34.

[21] 刘英文, 杨世伦, 罗向欣. 海平面上升的淹没效应和岸滩冲淤 对潮间带湿地面积影响的分离估算. 上海国土资源, 2011, 32 (3) : 18-22.

[24] 陈燕萍, 杨世伦, 史本伟, 李鹏, 朱建荣. 潮滩上波高的时空 变化及其影响因素——长江三角洲海岸为例. 海洋科学进 展, 2012, 30(3) : 317-327.

[25] 唐玉姝, 王否, 贾建伟, 李艳丽, 张文佺, 王红丽, 付小花, 乐毅全. 促淤等人为扰动对长江口滩涂湿地土壤微生物呼吸 的影响. 生态学报, 2010, 30(18): 5022-5032.

[26] 李九发, 戴志军, 应铭, 吴荣荣, 付桂, 徐海根. 上海市沿海 滩涂土地资源圈围与潮滩发育演变分析. 自然资源学报, $2007,22(3)$ : 361-371.

[29] 杨云平, 李义天, 孙昭华, 訤咏阳. 长江口最大浑浊带悬沙浓 度变化趋势及成因. 地理学报, 2013, 68(9)：1240-1250. 


\section{ACTA ECOLOGICA SINICA Vol.34,No.12 June,2014(Semimonthly) CONTENTS}

Development history and future research priorities of landscape ecology in China

CHEN Liding, LI Xiuzhen, FU Bojie, et al (3129)

Research review on effects of urban landscape pattern changes on water environment

HUANG Shuo, GUO Qinghai (3142)

A review of multifunctional landscape

TANG Qian, DING Shengyan (3151)

Compact development of space-limited city : a case study of Xiamen Island

HUANG Shuo, GUO Qinghai, TANG Lina (3158)

Analysis of factors contributing to the cooling effects of Purple Mountain Forest Park

YAN Weijiao, KONG Fanhua, YIN Haiwei, et al (3169)

Impacts of structure characteristics on the thermal environment effect of city parks

FENG Yueyi, HU Tangao, ZHANG Lixiao (3179)

Suitability assessment for building land consolidation on gentle hillside based on OWA operator: a case in Dali Bai Nationality

Borough in Yunnan, China

LIU Yanxu, PENG Jian, HAN Yinan, et al (3188)

Optimization of land use pattern based on eco-security : a case study in the huangfuchuan watershed

YU Feng, LI Xiaobing, WANG Hong (3198)

Analysis of land use/cover change from 2000 to 2010 and its driving forces in Manas River Basin, Xinjiang

LIU Jinwei, JIN Tiantian, LIU Guohua, et al (3211)

Dynamic trend analysis of land use change in the ganjiang upstream watershed by using RS and GIS techniques

LU Yanfei, PENG Fang, WAN Yun, et al (3224)

Landscape pattern dynamics and driving forces analysis in the Sanjiang Plain from 1954 to 2010

LIU Jiping, ZHAO Dandan, TIAN Xuezhi, et al (3234)

Optimizing theory and case studies of cultivated slope land in the center of three gorges reservoir area based on patch-scale land

evaluation

WANG Yongyan, LI Yangbing, SHAO Jingan, et al (3245)

Spatial-temporal evolution of land use and landscape pattern of the mountain-basin system in Guizhou Province

LI Yangbing, YAO Yuanwen, XIE Jing, et al (3257)

Spatio-temporal simulation of land cover scenarios in southwestern of China

LI Jing, FAN Zemeng, YUE Tianxiang (3266)

Gradient analysis of dry valley of Minjiang River landscape pattern, based on moving window method

ZHANG Lingling, ZHAO Yonghua, YIN Sha, et al (3276)

Study on spatio-temperal change of Tibetan Antelope's habitat based on vegetation coverage

ZHAO Haidi, LIU Shiliang, DONG Shikui, et al (3285)

Spatial heterogeneity of soil microbial biomass carbon, nitrogen, and phosphorus in sloping field in a groge Karst region,

Southwest China

FAN Fujing, HUANG Guoqin, SONG Tongqing, et al (3293)

Characteristics of soil microbial populations and biomass under different ecosystems in a canyon karst region

TAN Qiujin, SONG Tongqing, PENG Wanxia, et al (3302)

Spatial and temporal dynamics of land use and its influence on ecosystem service value in Yangtze River Delta

LIU Guilin, ZHANG Luocheng, ZHANG Qian (3311)

Evaluation of tourism dynamic landscape along Qinghai-Tibet railway based on the visual corridor

ZHANG Ruiying, XI Jianchao, YAO Yulong, et al (3320)

A study of spatial evolution characteristics of rural settlements and influences of landscape patterns on their distribution using GIS and RS REN Ping, HONG Buting, LIU Yin, et al (3331) 
Assessing the ecosystem conservation status and priority: a case study from Jiangxi Province, China

FAN Naiqing, ZHANG Yuxin, LÜ Yihe, et al (3341)

The impact of salt marsh change on sediment accumulation and wave attenuation at the East Chongming Island

REN Linjing, LI Xiuzhen, YANG Shilun, et al (3350)

Landscape classification system based on climate, landform, ecosystem : a case study of Xinjiang area

SHI Qingdong, WANG Zhi, HE Longmei, et al (3359)

Analysis of landscape pattern evolution characteristic in the hilly and gully area of loess plateau: a case study in Yan'an City,

Shaanxi Province

ZHONG Lina, ZHAO Wenwu, LV Yihe, et al (3368)

Analysis of the characteristics of agro-landscape heterogeneity under the different disturbances:a case study of Gongyi City

ZHANG Xiaoyang, LIANG Guofu, DING Shengyan (3378)

Classification and ordination of grassland landscape in the Shanxi Plateau

ZHANG Xianping, LI Zhiqin, WANG Mengben, et al (3386)

Analysis of factors affecting mountainous land surface temperature in the summer: a case study over Mount Tai

SUN Changfeng, KONG Fanhua, YIN Haiwei, et al (3396)

Research on spatial distribution and influencing factor of soil moisture in typical depression area of karst region

ZHANG Jiguang, SU Yirong, CHEN Hongsong, et al (3405)

Landscape heterogeneity of mountainous and hilly area in the western Henan Province based on moving window method

LI Dongke, DING Shengyan, LIANG Guofu, et al (3414)

Trends in vegetation and their responses to climate and topography in northwest Guangxi

TONG Xiaowei, WANG Kelin, YUE Yuemin, et al (3425)

Landscape pattern analysis on change of fractional vegetation cover between karst and no-karst areas: a case study in Hechi

District, Guangxi Zhuang Autonomous Region

WANG Mingchong, WANG Xizhi, LIANG Zhaoxiong, et al (3435)

Multi-scale effects for landscape metrics and species diversity under the different disturbance: a case study of Gongyi City

DONG Cuifang, LIANG Guofu, DING Shengyan, et al (3444)

Spatial heterogeneity of soil organic carbon and total nitrogen concentrations in a Lithocarpus glaber-Cyclobalanopsis glauca evergreen broadleaved forest

YANG Dan, XIANG Wenhua, FANG Xi, et al (3452)

The characteristics and regeneration of the Choerospondias axillaries broad-leaved community in the hilly region of central Hunan

Province, China

YI Hao, DENG Xiangwen, XIANG Wenhua, et al (3463)

Factors influencing the spatial distribution of vegetation carbon density in karst landscapes of Northwest Guangxi: a case study

based on radial basis function network model

ZHANG Mingyang, WANG Kelin, DENG Zhenhua, et al (3472) 


\section{《生态学报》2014 年征订启事}

《生态学报》是由中国科学技术协会主管, 中国生态学学会、中国科学院生态环境研究中心主办的生态学 高级专业学术期刊,创刊于 1981 年,报道生态学领域前沿理论和原始创新性研究成果。坚持“百花齐放,百家 争鸣” 的方针, 依靠和团结广大生态学科研工作者, 探索生态学奥秘, 为生态学基础理论研究搭建交流平台, 促进生态学研究深人发展, 为我国培养和造就生态学科研人才和知识创新服务、为国民经济建设和发展服务。

《生态学报》主要报道生态学及各分支学科的重要基础理论和应用研究的原始创新性科研成果。特别欢 迎能反映现代生态学发展方向的优秀综述性文章; 研究简报; 生态学新理论、新方法、新技术介绍; 新书评价和 学术、科研动态及开放实验室介绍等。

《生态学报》为半月刊,大 16 开本, 280 页, 国内定价 90 元/册, 全年定价 2160 元。

国内邮发代号: 82-7,国外邮发代号: M670

标准刊号:ISSN 1000-0933 CN 11-2031/Q

全国各地邮局均可订阅，也可直接与编辑部联系购买。欢迎广大科技工作者、科研单位、高等院校、图书 馆等订阅。

通讯地址: 100085 北京海淀区双清路 18 号 电

E-mail: shengtaixuebao@ rcees.ac.cn
网

话: (010)62941099; 62843362

址: www.ecologica.cn

编辑部主任 孔红梅 执行编辑 刘天星 段 靖

\author{
生 态 学 报 \\ (SHENGTAI XUEBAO) \\ (半月刊 1981 年 3 月创刊)
}

第 34 卷 第 12 期 (2014 年 6 月)

\section{ACTA ECOLOGICA SINICA}

( Semimonthly, Started in 1981)

Vol. 34 No. 12 (June, 2014)

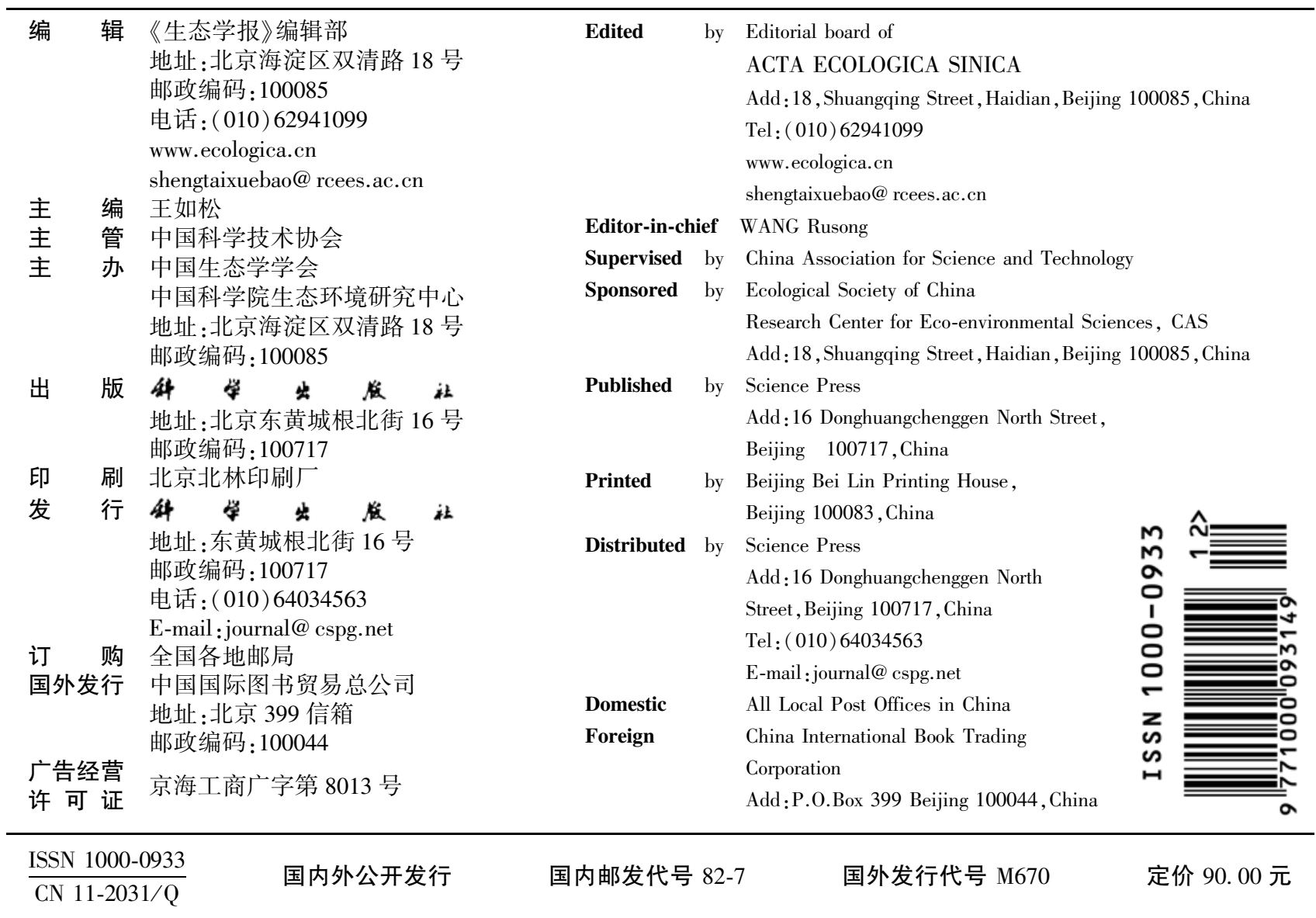

